\title{
Effectiveness of proximal intra-operative salvage Palmaz stent placement for endoleak during endovascular aneurysm repair
}

\author{
Y Law *, YC Chan, Stephen WK Cheng
}

\section{A B S T R A C T}

Introduction: The use of a proximal Palmaz stent is a well-recognised technique to treat proximal endoleak in endovascular aortic repair. This study aimed to report the effectiveness and safety of an intra-operative Palmaz stent for immediate type 1a endoleak in Hong Kong patients.

Methods: This case series was conducted at a tertiary hospital in Hong Kong. In a cohort of 494 patients who underwent infrarenal endovascular aortic repair from July 1999 to September 2015, $12(2.4 \%)$ received an intra-operative proximal Palmaz stent for type 1a endoleak. Immediate and subsequent proximal endoleak on follow-up image was documented.

Results: Morphological review of the pre-repair aneurysm neck showed five conical, one funnel, five cylindrical and one undetermined short neck, with a median neck angle of 61 degrees (range, 19-109 degrees). Stent grafts used included seven Cook Zenith, one Cook Aorto-Uni-Iliac device, three Metronic Endurant, and one TriVascular Ovation. Eleven Palmaz stents were placed successfully as intended, but one of them was accidentally placed too low. Of the 12 type 1a endoleaks, postoperative

This article was published on 24 Oct 2016 at www.hkmj.org. imaging revealed immediate resolution of eight whilst four had improved. After a median follow-up

of 16 (range, 1-59) months, none of the subsequent imaging showed a type 1a endoleak. The mean size of the aneurysm sac reduced from $7.4 \mathrm{~cm}$ preoperatively to $7.3 \mathrm{~cm}$ at 1 month, $6.9 \mathrm{~cm}$ at 6 months, $7.1 \mathrm{~cm}$ at 1 year, and $6.1 \mathrm{~cm}$ at 2 years postoperatively. None of these patients required aortic reintervention or had device-related early- or mid-term mortality. One patient required delayed iliac re-interventions for an occluded limb at 10 days post-surgery.

Conclusion: In our cohort, Palmaz stenting was effective and safe in securing proximal sealing and fixation.

\section{Hong Kong Med J 2016;22:538-45 \\ DOI: $10.12809 / \mathrm{hkmj} 154799$}

Y Law *, MB, BS, FRCS (Edin)

YC Chan, MB, BS, FRCS (Eng)

SWK Cheng, MB, BS, FRCS (Edin)

Division of Vascular and Endovascular Surgery, Department of Surgery,

The University of Hong Kong, Queen Mary Hospital, Pokfulam, Hong Kong

* Corresponding author: lawyuksimpson@gmail.com

This paper was presented in abstract form at the 15th Congress of Asian Society for Vascular Surgery (ASVS) Hong Kong, 5-7 September 2014 Hong Kong.

New knowledge added by this study

- Palmaz stenting is effective and safe as a salvage treatment of proximal endoleak during endovascular aortic repair (EVAR).

Implications for clinical practice or policy

- Appropriate patient selection, meticulous preoperative planning, and diligent follow-up ensured the ultimate success of EVAR.

- A Palmaz stent should always be readily available during EVAR especially for aneurysms with a hostile aortic neck.

\section{Introduction}

Hostile proximal infrarenal aortic neck is often considered one of the relative contra-indications for infrarenal endovascular aortic repair (EVAR), but large multicentre registries have shown that more EVARs have been performed worldwide beyond manufacturers' indications. ${ }^{1-3}$ Data from the EUROSTAR Registry more than a decade ago looking at aneurysm morphology and procedural details of 2272 patients showed that perioperative type 1a endoleak was significantly associated with a larger angulated infrarenal neck with thrombus. ${ }^{4}$ Other morphological features included short aortic neck length, large sac diameter, severe angulation, and conical neck configuration. ${ }^{5}$ Endoleak is defined as the persistence of blood flow outside the lumen of an endovascular graft but within an aneurysm sac. Type 1a endoleak is a leak around the proximal graft attachment site. They are clinically important since they can lead to continual aneurysm enlargement 
and eventual rupture. ${ }^{6}$

Although the development of renal and mesenteric fenestration or branched stent graft technology to extend the landing zone more proximally may overcome type 1a endoleaks, these devices may not be ideal because of regulations, complexity, and manufacturing delays. ${ }^{7}$ In addition, contemporary published literature does not provide sufficiently strong evidence to warrant a change in treatment guidelines for juxtarenal or short-neck aneurysm. ${ }^{8}$

The use of a proximal giant Palmaz stent (Cordis Corp, Fremont [CA], US) is a wellrecognised technique to manage a type 1a endoleak intra-operatively.9-12 A prophylactic Palmaz stent inserted for hostile neck has also been reported. ${ }^{13-15}$ The aim of this study was to report the effectiveness and safety of an intra-operative Palmaz stent for an immediate type 1a endoleak.

\section{Methods}

\section{Patient selection}

Patients with an infrarenal abdominal aortic aneurysm (AAA) who had undergone EVAR were retrospectively reviewed for the period 1 July 1999 to 30 September 2015. Data were extracted from prospectively collected computerised departmental database, supplemented by patient records. This study was done in accordance with the principles outlined in the Declaration of Helsinki. All patients had undergone a preoperative fine-cut computed tomographic (CT) scan and careful preoperative planning with a conclusion that EVAR was feasible. All our patients who underwent EVAR had preoperative three-dimensional aortic anatomy examined using the stationary TeraRecon Aquarius workstation (TeraRecon, San Mateo [CA], US) that rapidly manipulates all preoperative data sets in the Digital Imaging and Communications in Medicine, and examines the aortic morphology. These details would be difficult to appreciate on twodimensional planar CT imaging, especially in those with inadequate short hostile neck. Those patients who were deemed unsuitable for infrarenal sealing would either undergo open repair or, more recently, fenestrated or adjunctive EVAR (such as chimney technique).

Cook Zenith (Cook Medical, Bloomington [IN], US), Medtronic Endurant (Medtronic Inc, Minneapolis [MN], US), and TriVascular Ovation (TriVascular Inc, Santa Rosa [CA], US) stent grafts were most commonly used. We sometimes extended the manufacturers' indications of use to include difficult aortic necks. All operations were performed in our institution, a tertiary vascular referral centre, by experienced vascular specialists in a hybrid endovascular suite (Siemens Artis zee

\section{血管腔內主動脈瘤修復過程中使用近端修復 Palmaz支架置入來阻止血管滲漏的成效 羅旭、陳燿志、鄭永強}

引言：採用近端Palmaz支架來阻止血管腔內主動脈瘤修復過程 (EVAR) 中近端血管滲漏是一種公認的技術。本研究旨在報告出現 $1 \mathrm{a}$ 型血管滲漏的香港患者使用Palmaz支架的有效性和安全性。

方法：本病例系列在香港一間三級醫院內進行。1999年7月至2015年 9 月期間共有 494 名患者接受腎下EVAR, 其中 12 人 ( $2.4 \%)$ 接受術中 近端Palmaz支架以阻止 $1 \mathrm{a}$ 型血管滲漏, 並記錄術後即時和隨後成像以 觀察近端血管滲漏的情況。

結果：EVAR術前動脈瘤頸有5個圓錐形、1 個漏斗形、5個圓柱形和 1個未知的短頸, 動脈瘤頸角度中位數為61度（介乎19-109度）。使 用的支架有Cook Zenith（7例）、Cook Aorto-Uni-Iliac（1例）

Metronic Endurant（3例）和TriVascular Ovation（1例）。成功達 成預期放置Palmaz支架位置有 11 例, 另 1 例位置太低。12例 1 a 型血管 滲漏中, 成像顯示術後 8 例消失, 4 例有改善。中位數為 16 個月的隨訪 期後（介乎1-59個月）的成像並無 $1 \mathrm{a}$ 型血管滲漏。動脈瘤囊由術前平 均 $7.4 \mathrm{~cm}$ 減至術後的 $7.3 \mathrm{~cm}$ (1個月）、 $6.9 \mathrm{~cm}$ (6個月 )、 $7.1 \mathrm{~cm}$ ( 1 年) 和 $6.1 \mathrm{~cm}$ (2年)。研究中並無患者須再次接受介入主動脈術 或者與設備有關的早發或中期死亡病例。1名有肢體閉塞的病人在術 後 10 天需要髂動脈再干預。

結論：研究結果顯示Palmaz支架置入術在近端密封和固定的層面上是 安全和有效的。

Multipurpose System; Siemens, Erlangen, Germany). Post-deployment balloon moldings with Coda balloon (Cook Medical, Bloomington [IN], US) and completion angiograms with power injection were performed in all patients.

\section{Proximal Palmaz stent placement}

In the event of proximal endoleak on completion angiogram, further balloon molding would be attempted. Persistent endoleak was managed with balloon expandable giant Palmaz stent P4014 (Cordis Corp). Our preference was for the Palmaz stent to be positioned at the infrarenal region over the fabric of the stent graft, so as not to jeopardise any future chance of proximal extension with a renal or mesenteric fenestrated cuff. They would be crimped on a Coda balloon (maximum inflated diameter, 40 $\mathrm{mm}$ ) and railed through a stiff guidewire to the top neck.

\section{Preoperative aneurysm neck morphological analysis}

Cause of proximal endoleak was usually hostile neck. We focused on aortic infrarenal neck anatomy where the Palmaz stent was placed and exerted its effect. All preoperative CT scans were analysed. Measurement was automatically calculated by computer software Aquarius iNtuition Client version 4.4 (TeraRecon 
Inc), after a median centre line path (MCLP) was drawn. We used definitions of neck measurement as defined by Filis et $\mathrm{al}^{16}$ :

(1) Neck length is calculated between the point of MCLP at the orifice of the lower renal artery and MCLP at the start of the aneurysm.

(2) Neck diameter is measured on the orthogonal cross-section of the neck, from the outer wall to the outer wall. It is measured at the lower renal artery level, $1 \mathrm{~cm}$ and $2 \mathrm{~cm}$ below.

(3) Neck angle is the angle between the axis of the neck (straight line between the MCLP of the aorta at the level of the orifice of the lower renal artery and the MCLP of the aorta at the start of the aneurysm) and the axis of the lumen of the aneurysm (straight line between the MCLP at the start of the aneurysm and the MCLP at the end of the aneurysm).

(4) Neck morphology (Fig 1):

(a) Funnel shape is defined as $20 \%$ decrease in neck area between the level of the lower renal artery and $2 \mathrm{~cm}$ below.

(b) Conical shape is defined as $20 \%$ increase in neck area between the level of the renal artery and $2 \mathrm{~cm}$ below.

(c) Cylindrical shape is defined between the above two.

(d) Shape is undetermined if neck length is less than $2 \mathrm{~cm}$.

\section{Clinical and radiological outcomes}

Immediate radiological result following Palmaz stent placement was reported. Any procedural mortality or morbidity was recorded. Our departmental protocol recommends postoperative imaging, either CT scan or duplex scan, at 1 to 3 months, then every 6 months for the first 2 years, and annually thereafter. These were supplemented by X-ray to detect any stent fracture or migration. Any endoleak detected during follow-up was reported as well as any alteration in sac size. Follow-up was dated to the most recent objective imaging available.

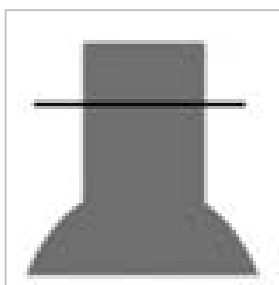

Cylindrical

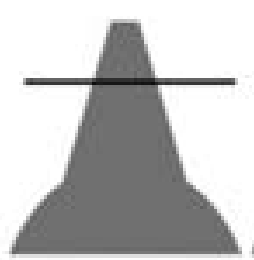

Conical

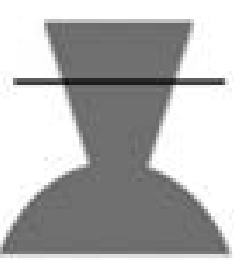

Funnel
FIG I. Illustration of neck morphology

\section{Results}

\section{Patient population}

During the study period 1 July 1999 to 30 September 2015, a total of 842 AAA surgeries were performed, of which 320 (38\%) were open repair and 522 (62\%) were endovascular repair (28 fenestrated/branched EVAR and 494 infrarenal EVAR). In a cohort of 494 patients with infrarenal EVAR, 12 (2.4\%) received an intra-operative proximal Palmaz stent for type 1a endoleak that was noticed on completion angiogram. No patients received prophylactic Palmaz stent for difficult neck anatomy.

Patient demographics are summarised in Table 1. The median age was 84 (range, 58-95) years. All had undergone elective surgery for asymptomatic AAA. The median AAA size was $7.6 \mathrm{~cm}$ (range, 5.0-9.4 cm). Seven patients received a Cook Zenith stent graft, one patient a Cook Aorto-Uni-Iliac device, three had Metronic Endurant stent grafts, and one had TriVascular Ovation stent graft. The occurrence of type 1a endoleak was more common in recent years (Table 2).

\section{Analysis of aneurysm neck morphology}

Table 2 summarises the neck morphologies of our cohort. Morphological review of the pre-EVAR aneurysm neck showed five conical, one funnel, five cylindrical, and one undetermined short necks. The

TABLE I. Baseline characteristics of 12 patients

\begin{tabular}{|c|c|}
\hline Characteristic & Data* \\
\hline Age (years) & $84(58-95)$ \\
\hline Sex (male / female) & $10 / 2$ \\
\hline \multicolumn{2}{|l|}{ Co-morbidities } \\
\hline Smoking & $4(33)$ \\
\hline Diabetes mellitus & $1(8)$ \\
\hline Hypertension & $8(67)$ \\
\hline Cardiac disease & $7(58)$ \\
\hline Pulmonary disease & $2(17)$ \\
\hline Renal disease & $3(25)$ \\
\hline Cerebral vascular accident & $3(25)$ \\
\hline ASA grade 3 & $12(100)$ \\
\hline Aneurysm size (cm) & $7.6(5.0-9.4)$ \\
\hline \multicolumn{2}{|l|}{ Stent grafts used } \\
\hline Cook Zenith bifurcated & 7 \\
\hline Cook Aorto-Uni-Iliac & 1 \\
\hline Metronic Endurant & 3 \\
\hline TriVascular Ovation & 1 \\
\hline Elective procedure & $12(100)$ \\
\hline
\end{tabular}


TABLE 2. Aneurysm neck morphology

\begin{tabular}{|c|c|c|c|c|c|c|}
\hline \multirow{2}{*}{$\begin{array}{l}\text { Patient } \\
\text { No. }\end{array}$} & \multicolumn{4}{|c|}{ Aneurysm neck morphology } & \multirow[t]{2}{*}{ Year of operation } & \multirow[t]{2}{*}{ Brand of stent graft } \\
\hline & Neck length (mm) & $\begin{array}{l}\text { Neck diameters at lowest } \\
\text { renal artery, } 10 \mathrm{~mm} \text { and } \\
20 \mathrm{~mm} \text { below }(\mathrm{mm})\end{array}$ & Neck angle & Neck morphology & & \\
\hline 1 & 36.8 & $\begin{array}{l}32.7 \\
31.8 \\
29.2\end{array}$ & $88.9^{\circ}$ & Funnel & 2005 & Cook Zenith \\
\hline 2 & 21.1 & $\begin{array}{l}24.4 \\
28.7 \\
29.2\end{array}$ & $79.8^{\circ}$ & Conical & 2006 & Cook Zenith \\
\hline 3 & 50.1 & $\begin{array}{l}26.6 \\
29.8 \\
30.7\end{array}$ & $18.6^{\circ}$ & Conical & 2011 & Cook Zenith \\
\hline 4 & 13.8 & $\begin{array}{l}22.1 \\
23.8\end{array}$ & $109.0^{\circ}$ & Undetermined & 2011 & Cook Zenith \\
\hline 5 & 21.5 & $\begin{array}{l}21.3 \\
23.4 \\
26.9\end{array}$ & $59.2^{\circ}$ & Conical & 2012 & Cook Zenith \\
\hline 6 & 27.9 & $\begin{array}{l}25.6 \\
25.8 \\
25.0\end{array}$ & $97.1^{\circ}$ & Cylindrical & 2012 & Cook Zenith \\
\hline 7 & 25.0 & $\begin{array}{l}22.7 \\
22.2 \\
23.1\end{array}$ & $69.6^{\circ}$ & Cylindrical & 2012 & Cook Aorto-Uni-lliac \\
\hline 8 & 21.4 & $\begin{array}{l}28.2 \\
30.7 \\
31.3\end{array}$ & $32.3^{\circ}$ & Cylindrical & 2012 & Medtronic Endurant \\
\hline 9 & 20.6 & $\begin{array}{l}23.7 \\
26.7 \\
28.4\end{array}$ & $33.8^{\circ}$ & Conical & 2013 & Cook Zenith \\
\hline 10 & 20.9 & $\begin{array}{l}24.5 \\
27.0 \\
27.0\end{array}$ & $63.1^{\circ}$ & Cylindrical & 2015 & Medtronic Endurant \\
\hline 11 & 25.5 & $\begin{array}{l}22.7 \\
25.0 \\
20.5\end{array}$ & $39.6^{\circ}$ & Cylindrical & 2014 & Medtronic Endurant \\
\hline 12 & 21.7 & $\begin{array}{l}18.5 \\
19.6 \\
25.6\end{array}$ & $48.0^{\circ}$ & Conical & 2015 & TriVascular Ovation \\
\hline
\end{tabular}

median neck angle was 61 degrees (range, 19-109 degrees). Use of the stent graft was outside of the manufacturer's guidelines in $\operatorname{six}(50 \%)$ patients. Most patients had one or more features of hostile neck, rendering them at high risk of proximal endoleak.

\section{Radiological outcomes}

All 12 patients had persistent proximal type 1a endoleak after stent graft placement with standard balloon molding. Placement of a giant Palmaz stent in the infrarenal position was technically successful in all cases, although one Palmaz stent was placed too low and lodged in one of the iliac limbs. Nonetheless, it served its function well in correcting the proximal endoleak (Figs 2 and 3). Immediate resolution of the endoleak was achieved in eight (67\%); whilst four (33\%) had improved but persistent leak at completion of the procedure.

\section{Clinical outcomes}

After a median follow-up of 16 (range, 1-59) months, no patient had a type 1a endoleak on subsequent imaging, either $\mathrm{CT}$ scan or duplex ultrasound scan. All patients had at least one postoperative CT scan. Patient 2 had a type 1c endoleak from an embolised left internal iliac artery that was managed conservatively. Patients 9 and 11 had a type 2 endoleak, also managed conservatively. All had shrinkage of sac size. Sac size of the aneurysms decreased from a mean of $7.4 \mathrm{~cm}$ pre-EVAR to 7.3 $\mathrm{cm}, 6.9 \mathrm{~cm}, 7.1 \mathrm{~cm}$, and $6.1 \mathrm{~cm}$ at 1 month, 6 months, 1 year, and 2 years post-EVAR, respectively (Fig 4). Routine X-ray surveillance did not reveal any Palmaz stent fracture or migration.

One patient required secondary endovascular re-intervention for occluded left iliac limb at day 10 postoperatively. It was due to a tortuous iliac system 


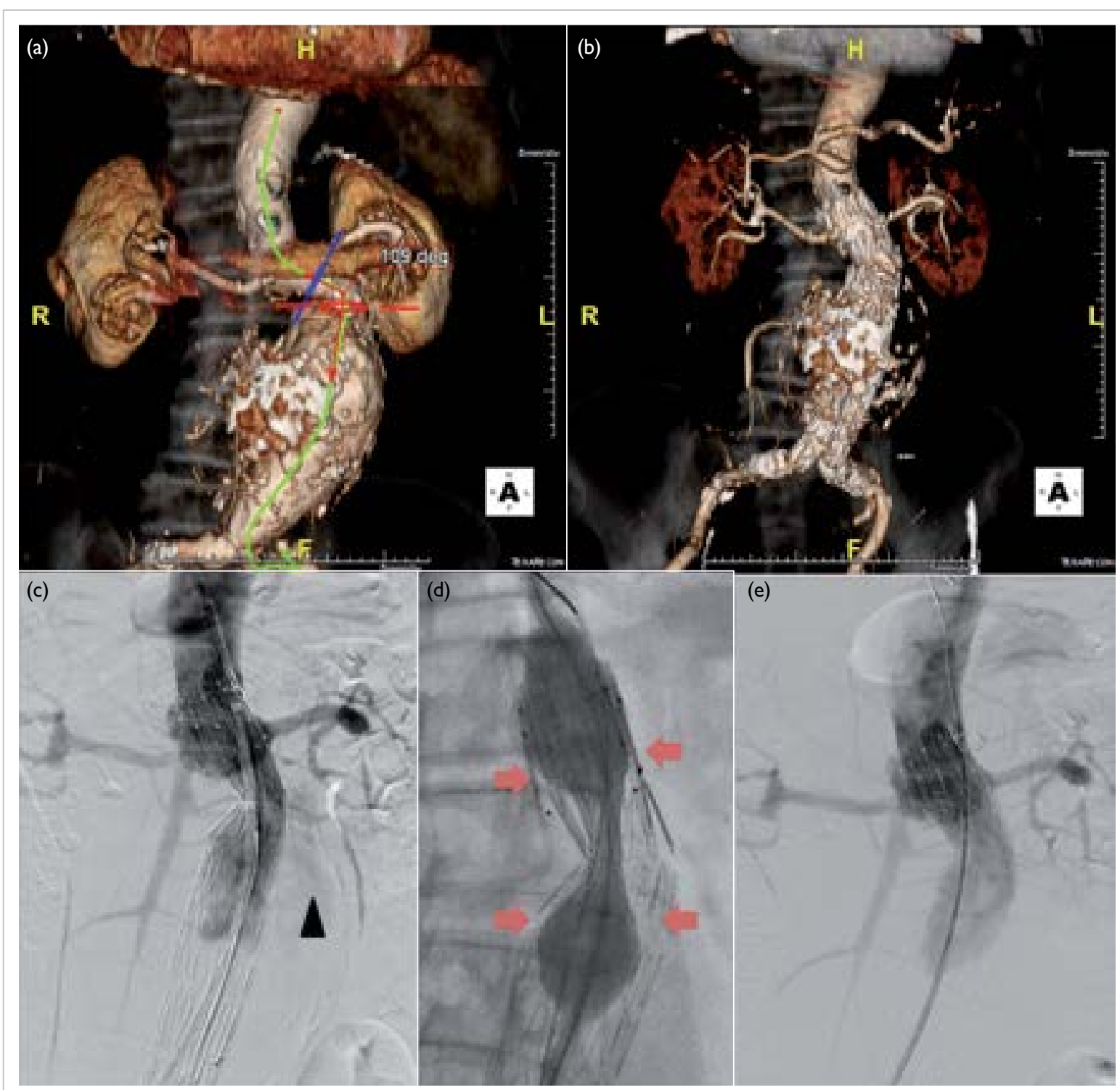

FIG 2. Abdominal aortic aneurysm of patient 4

(a) Preoperative computed tomographic (CT) scan showing a short and angulated neck; the patient underwent endovascular aortic repair. (c) Completion angiogram showing type la endoleak from the left side (arrowhead). (d) Palmaz stent being inserted (red arrows) and (e) proximal endoleak is resolved. (b) Postoperative CT scan showing no endoleak

causing an acute bend to the stent graft limb. There was no other reported secondary intervention. Seven patients have since died (at 6, 9, 16, 16, 20, 24, and 59 postoperative months) from non-aneurysm-related causes. Five remain alive at the time of writing.

\section{Discussion}

Hostile aortic neck anatomy often precludes endovascular treatment of AAA. It has been shown in large clinical cohorts that up to $42 \%$ of EVARs are performed outside the instructions for use for commercially available stent grafts., ${ }^{3,17-19}$ Multiple measures have been developed to include more of these difficult necks for endovascular treatment.
Evolution of stent graft design including suprarenal fixation $^{20}$ and renal and mesenteric fenestration ${ }^{21}$ are examples. Adjunctive neck measures, eg endostapling, ${ }^{22,23}$ proximal fibrin glue embolisation, ${ }^{24}$ open aortic neck banding, ${ }^{25}$ and proximal covered cuff extension ${ }^{10}$ may be used in cases of perioperative type 1a endoleak following EVAR. Endostapling and glue embolisation, though minimally invasive, are not always feasible and risk major aortic injury. Open aortic neck banding requires laparotomy. Proximal cuff extension is only feasible if there is an additional sealing zone to the most caudal renal artery. Since we routinely landed our stent graft at the level of the lowest renal artery, this technique was not usually practical. The simplest and most well-recognised 


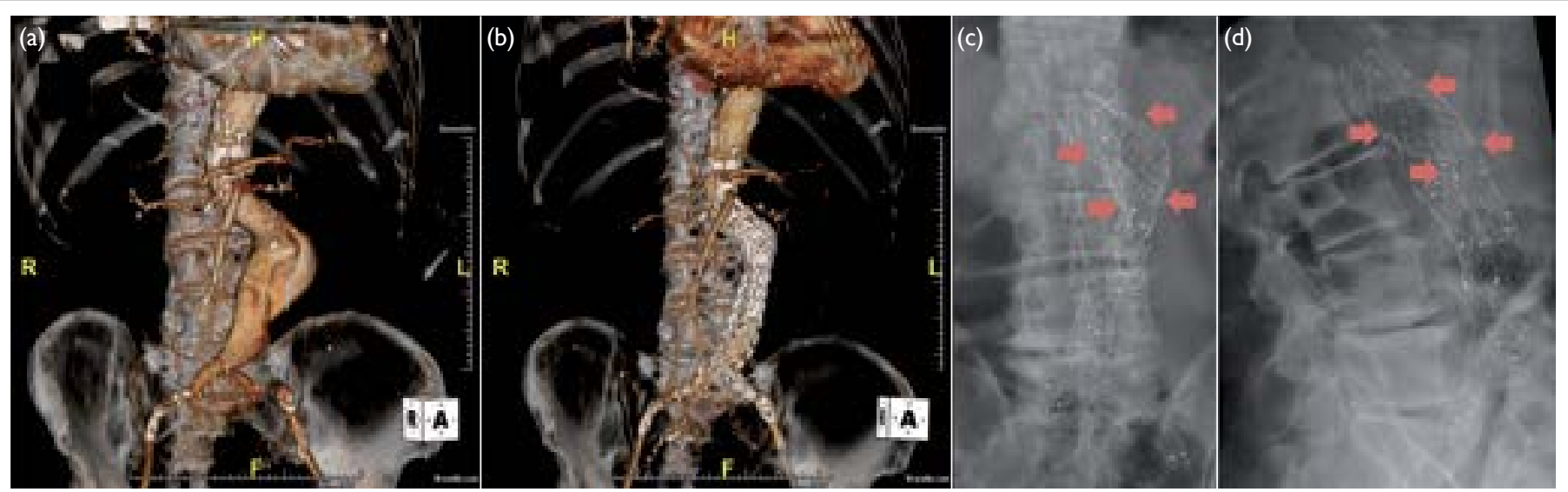

FIG 3. Aneurysm of patient 10

(a) Preoperative computed tomographic (CT) scan showing an angulated neck. (b) Postoperative CT reconstruction. (c and d) X-ray scans showing the Palmaz stent was placed too low and became lodged in the proximal right limb (red arrows). Nonetheless the proximal part of the Palmaz stent served well to prevent proximal endoleak

manoeuvre remains placement of a proximal Palmaz stent.

The morphology of the infrarenal aortic neck is important in securing the proximal landing zone. Three-dimensional workstation planning has been considered useful by many ${ }^{26,27}$; for example, Sobocinski et $\mathrm{al}^{28}$ showed that it reduced the rate of type 1 endoleaks and Velazquez et $\mathrm{al}^{29}$ indicated that it decreased the rate of extra iliac extension. We emphasise the importance of proper pre-EVAR planning, as this is one of the obvious factors that may compromise long-term durability and outcome. The fact that half of stent graft usage in our series was outside the instructions for use and most patients had one or more hostile neck feature rendered them at high risk of proximal endoleak. Under these circumstances, a Palmaz stent should always be readily available during EVAR.

Multiple series have reported their experience in its successful use. Early study by Dias et $\mathrm{al}^{9}$ reported nine patients who received a Palmaz stent and in whom aneurysm remained excluded at a median follow-up of 13 months (range, 6-24 months). Rajani et $\mathrm{al}^{10}$ reported successful treatment of intra-operative type 1 endoleak with Palmaz stent in 27 patients who had no recurrence at follow-up, although length of follow-up was not mentioned. Arthurs et $\mathrm{al}^{11}$ reported no type 1 endoleak in 31 patients after a median follow-up of 53 months (interquartile range, 14-91 months). The Palmaz stent was effective across a variety of available devices with suprarenal fixation (eg Cook Zenith) or infrarenal fixation (eg Gore Excluder; WL Gore \& Associates, Inc, Newark [DE], US). Our results are in agreement with these findings.

Other series have shown controversial

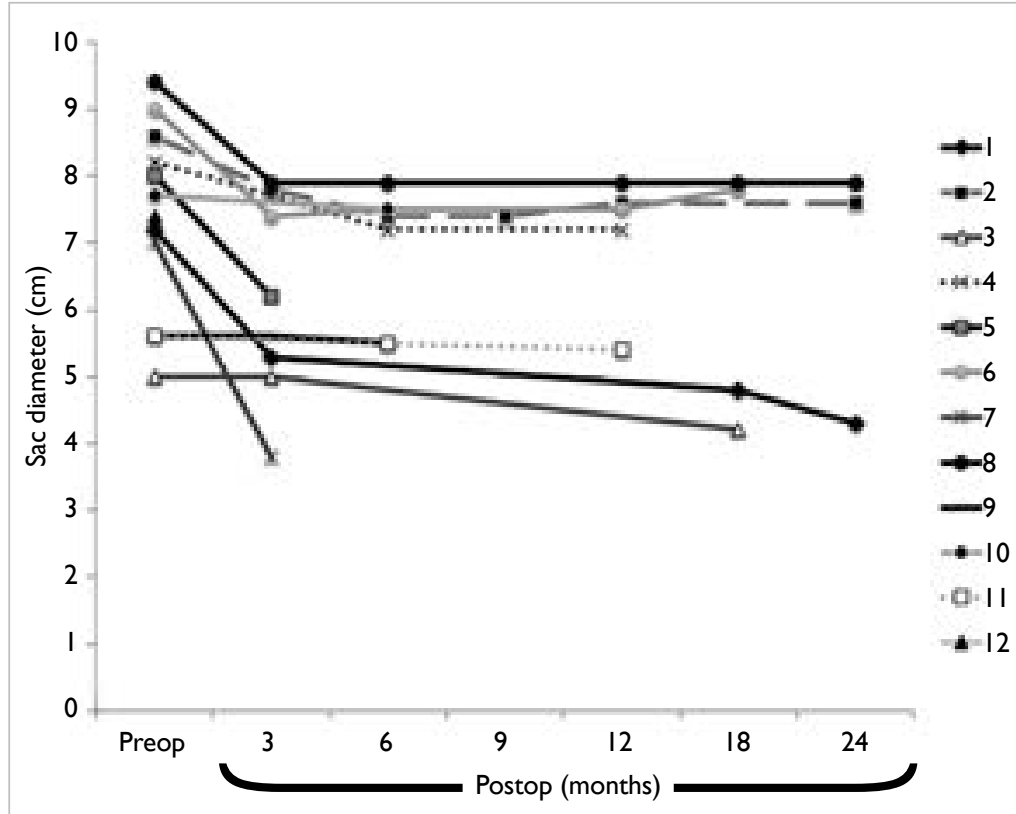

FIG 4. Alteration in sac size over time

Patient 2 developed type Ie endoleak, patients 9 and I I developed type 2 endoleaks

results. Farley et $\mathrm{al}^{15}$ reported 18 cases of Palmaz stent placement. Technical placement failed in one patient, in whom attempts at passing the access sheath to the proximal landing zone resulted in proximal migration of the main body of the aortic stent graft. An attempt at passage of the balloonmounted stent without sheath protection resulted in slippage of the stent from the balloon. The stent could not be retrieved and was deployed in the iliac limb. With a mean follow-up period of 254 days in the 17 successful Palmaz stent placements, one 
patient had unresolved type 1 endoleak. Malposition of the stent was not an unusual complication. ${ }^{30,31} \mathrm{Kim}$ et $\mathrm{al}^{32}$ described a deployment technique to ensure accuracy. Palmaz stent was asymmetrically handcrimped on an appropriately sized valvuloplasty balloon that assured the proximal aspect would deploy first.

Some series have advocated prophylactic Palmaz stent placement in hostile necks, including 15 patients reported by Cox et al. ${ }^{13}$ One (7\%) patient had secondary endoleak with intervention after a mean follow-up of 12 months. Qu and Raithel ${ }^{14}$ reported 117 cases of difficult neck treated with unibody Powerlink device (Endologix Inc, Irvine [CA], US). In this series, 83 (72.8\%) had proximal Palmaz stent as an adjunctive procedure. Proximal cuff extension was also used. The mean follow-up was 2.6 years (range, 4 months- 5 years). Results were satisfactory with an overall re-intervention rate of $5.3 \%$, and no device migration, conversion, or postEVAR rupture.

Palmaz stents were routinely placed at an infrarenal position in our unit on the basis that future extension with a fenestrated cuff is possible. If a transrenal position is adopted, the strut of the Palmaz stent, which is a very tight space, may hinder catheterisation of renal or visceral arteries should a fenestrated cuff be inserted. This is not absolute, however. Oikonomou et $\mathrm{al}^{33}$ reported a case of posttreatment with Powerlink stent graft and transrenal Palmaz stent. Treatment of proximal endoleak at 3 years after operation was successful by means of a proximal fenestrated graft. Selective catheterisation of both renal arteries and dilation of the stent struts prior to stent graft repair ensured that it would be feasible to catheterise the renal arteries through the fenestrated cuff.

There are limitations to this study. The retrospective nature of our cohort may risk inaccurate information. The efficacy of the Palmaz stent in aneurysms with short infrarenal neck may not be tested, as the majority were considered straight for custom-made fenestrated or branched EVAR. In our limited experience, a Palmaz stent is a valuable tool to expand the boundary of endovascular treatment for AAA.

\section{Conclusion}

Palmaz stent helps proximal sealing and fixation. In our experience, Palmaz stenting is effective and safe as a salvage treatment of immediate proximal endoleak during EVAR. We emphasise the importance of appropriate patient selection, preEVAR planning, and diligent follow-up.

\section{Declaration}

All authors have disclosed no conflicts of interest.

\section{References}

1. Bachoo P, Verhoeven EL, Larzon T. Early outcome of endovascular aneurysm repair in challenging aortic neck morphology based on experience from the GREAT C3 registry. J Cardiovasc Surg (Torino) 2013;54:573-80.

2. Matsumoto T, Tanaka S, Okadome J, et al. Midterm outcomes of endovascular repair for abdominal aortic aneurysms with the on-label use compared with the offlabel use of an endoprosthesis. Surg Today 2015;45:880-5.

3. Hoshina K, Hashimoto T, Kato M, Ohkubo N, Shigematsu K, Miyata T. Feasibility of endovascular abdominal aortic aneurysm repair outside of the instructions for use and morphological changes at 3 years after the procedure. Ann Vasc Dis 2014;7:34-9.

4. Buth J, Harris PL, van Marrewijk C, Fransen G. The significance and management of different types of endoleaks. Semin Vasc Surg 2003;16:95-102.

5. Stanley BM, Semmens JB, Mai Q, et al. Evaluation of patient selection guidelines for endoluminal AAA repair with the Zenith Stent-Graft: the Australasian experience. J Endovasc Ther 2001;8:457-64.

6. Fransen GA, Vallabhaneni SR Sr, van Marrewijk CJ, et al. Rupture of infra-renal aortic aneurysm after endovascular repair: a series from EUROSTAR registry. Eur J Vasc Endovasc Surg 2003;26:487-93.

7. Chuter T, Greenberg RK. Standardized off-the-shelf components for multibranched endovascular repair of thoracoabdominal aortic aneurysms. Perspect Vasc Surg Endovasc Ther 2011;23:195-201.

8. Ou J, Chan YC, Cheng SW. A systematic review of fenestrated endovascular repair for juxtarenal and shortneck aortic aneurysm: evidence so far. Ann Vasc Surg 2015;29:1680-8.

9. Dias NV, Resch T, Malina M, Lindblad B, Ivancev K. Intraoperative proximal endoleaks during AAA stentgraft repair: evaluation of risk factors and treatment with Palmaz stents. J Endovasc Ther 2001;8:268-73.

10. Rajani RR, Arthurs ZM, Srivastava SD, Lyden SP, Clair DG, Eagleton MJ. Repairing immediate proximal endoleaks during abdominal aortic aneurysm repair. J Vasc Surg 2011;53:1174-7.

11. Arthurs ZM, Lyden SP, Rajani RR, Eagleton MJ, Clair DG. Long-term outcomes of Palmaz stent placement for intraoperative type Ia endoleak during endovascular aneurysm repair. Ann Vasc Surg 2011;25:120-6.

12. Chung J, Corriere MA, Milner R, et al. Midterm results of adjunctive neck therapies performed during elective infrarenal aortic aneurysm repair. J Vasc Surg 2010;52:143541.

13. Cox DE, Jacobs DL, Motaganahalli RL, Wittgen CM, Peterson GJ. Outcomes of endovascular AAA repair in patients with hostile neck anatomy using adjunctive balloon-expandable stents. Vasc Endovascular Surg 2006;40:35-40.

14. Qu L, Raithel D. Experience with the Endologix Powerlink endograft in endovascular repair of abdominal aortic aneurysms with short and angulated necks. Perspect Vasc Surg Endovasc Ther 2008;20:158-66.

15. Farley SM, Rigberg D, Jimenez JC, Moore W, QuinonesBaldrich W. A retrospective review of Palmaz stenting of the aortic neck for endovascular aneurysm repair. Ann Vasc Surg 2011;25:735-9.

16. Filis KA, Arko FR, Rubin GD, Zarins CK. Three- 
dimensional CT evaluation for endovascular abdominal aortic aneurysm repair. Quantitative assessment of the infrarenal aortic neck. Acta Chir Belg 2003;103:81-6.

17. Walker J, Tucker LY, Goodney P, et al. Adherence to endovascular aortic aneurysm repair device instructions for use guidelines has no impact on outcomes. J Vasc Surg 2015;61:1151-9.

18. Igari K, Kudo T, Toyofuku T, Jibiki M, Inoue Y. Outcomes following endovascular abdominal aortic aneurysm repair both within and outside of the instructions for use. Ann Thorac Cardiovasc Surg 2014;20:61-6.

19. Lee JT, Ullery BW, Zarins CK, Olcott C 4th, Harris EJ Jr, Dalman RL. EVAR deployment in anatomically challenging necks outside the IFU. Eur J Vasc Endovasc Surg 2013;46:65-73.

20. Robbins M, Kritpracha B, Beebe HG, Criado FJ, Daoud Y, Comerota AJ. Suprarenal endograft fixation avoids adverse outcomes associated with aortic neck angulation. Ann Vasc Surg 2005;19:172-7.

21. Verhoeven EL, Vourliotakis G, Bos WT, et al. Fenestrated stent grafting for short-necked and juxtarenal abdominal aortic aneurysm: an 8-year single-centre experience. Eur J Vasc Endovasc Surg 2010;39:529-36.

22. Donas KP, Kafetzakis A, Umscheid T, Tessarek J, Torsello G. Vascular endostapling: new concept for endovascular fixation of aortic stent-grafts. J Endovasc Ther 2008;15:499503.

23. Avci M, Vos JA, Kolvenbach RR, et al. The use of endoanchors in repair EVAR cases to improve proximal endograft fixation. J Cardiovasc Surg (Torino) 2012;53:41926.

24. Feng JX, Lu QS, Jing ZP, et al. Fibrin glue embolization treating intra-operative type I endoleak of endovascular repair of abdominal aortic aneurysm: long-term result [in Chinese]. Zhonghua Wai Ke Za Zhi 2011;49:883-7.

25. Scarcello E, Serra R, Morrone F, Tarsitano S, Triggiani
G, de Franciscis S. Aortic banding and endovascular aneurysm repair in a case of juxtarenal aortic aneurysm with unsuitable infrarenal neck. J Vasc Surg 2012;56:20811.

26. Lee WA. Endovascular abdominal aortic aneurysm sizing and case planning using the TeraRecon Aquarius workstation. Vasc Endovascular Surg 2007;41:61-7.

27. Parker MV, O'Donnell SD, Chang AS, et al. What imaging studies are necessary for abdominal aortic endograft sizing? A prospective blinded study using conventional computed tomography, aortography, and three-dimensional computed tomography. J Vasc Surg 2005;41:199-205.

28. Sobocinski J, Chenorhokian H, Maurel B, et al. The benefits of EVAR planning using a 3D workstation. Eur J Vasc Endovasc Surg 2013;46:418-23.

29. Velazquez OC, Woo EY, Carpenter JP, Golden MA, Barker CF, Fairman RM. Decreased use of iliac extensions and reduced graft junctions with software-assisted centerline measurements in selection of endograft components for endovascular aneurysm repair. J Vasc Surg 2004;40:2227.

30. Gabelmann A, Krämer SC, Tomczak R, Görich J. Percutaneous techniques for managing maldeployed or migrated stents. J Endovasc Ther 2001;8:291-302.

31. Slonim SM, Dake MD, Razavi MK, et al. Management of misplaced or migrated endovascular stents. J Vasc Interv Radiol 1999;10:851-9.

32. Kim JK, Noll RE Jr, Tonnessen BH, Sternbergh WC 3rd. A technique for increased accuracy in the placement of the "giant" Palmaz stent for treatment of type IA endoleak after endovascular abdominal aneurysm repair. J Vasc Surg 2008;48:755-7.

33. Oikonomou K, Botos B, Bracale UM, Verhoeven EL. Proximal type I endoleak after previous EVAR with Palmaz stents crossing the renal arteries: treatment using a fenestrated cuff. J Endovasc Ther 2012;19:672-6. 